\title{
An Open Source Software Business Model For Law Enforcement And Justice Systems
}

\author{
B. Wayne Walters, University of Southern Mississippi, USA
}

\begin{abstract}
Software application projects that are being developed or planned for use in environments that have typically been distributed or marketed to outside organizations may now be posed with new parameters to consider. Not only are project managers and stakeholders confronted with the usual project constraints of scope, cost, time, and quality, but also new application development and distribution models must be given careful consideration. By application development and distribution models, I am referring to decisions to develop, market, or procure, open source or proprietary software code. This decision is not as much dependent on the development methodology as the distribution license used for the finished product. There is no secret that companies that develop proprietary software, whether systems or applications, usually devise strategies to obsolete their products so that the purchase of upgraded versions will be required. Support is often dropped from older version of software to force the purchase in new versions. In addition, vendors often try to lock their customers into their products by forcing huge investments in specialized employees, training, special hardware, unique features, and large initial capital outlays. Also, licenses often do not allow a sufficient timeframe to drop one product and move on to another brand. This paper will present an example of an open source software model for law enforcement and justice systems that will attempt to prevent many of the problems associated with procuring proprietary software. This model will describe how a federal grant can fund the development of a criminal justice suite of software that can be distributed without cost to any law enforcement or justice agency. The first module, a jail management system, has been completed and a business model has been developed for its open deployment.
\end{abstract}

Keywords: Open Source, Law Enforcement Software, Justice Software, Software Distribution

\section{COMPUTERS AND THEIR SOFTWARE}

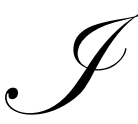
nnovation and creativity has presented today's society with many new ideas that are changing the way that life's activities are performed. In the mid-to-late 1990's, these ideas began merging and a true paradigm shift in the way our personal and professional lives are conducted evolved. Most of these changes came about because of advances in electronics, communications, and computer related technologies. Instrumental in these changes was the broad acceptance of the Internet as a part of everyday life. No longer did the average citizen fear the computer. Computers in the home, as well as the office, brought about a new acceptance that a computer was just a tool that could be used for communication and information.

This rapid change in acceptance helped bring about this paradigm shift. No longer was it necessary to do banking in person or shop for goods in brick and mortar outlets. Companies began to realize that field sales forces could be reduced. Now customers could find even more information, and comparative information, on-line quickly.

Behind most of these innovations is software. Software drives cell phones, GPS systems, and other mobile devices. Software is vital to the delivery of information across the Internet. Software is becoming pervasive in lives. It is intangible, but always active. 
But what is software? Software is what was often called the "computer brain" in the past. Software is the instructions that tell the computer what to do. Without software a computer is just silicon, copper, and a few pieces of other materials. Software interprets what is to be accomplished. It helps to translate data into information.

Software development is an involved, systematized, process of organizing the detail steps that are to be accomplished. These steps can be so complex that many software systems are seldom, truly, problem-free because of the many combinations of what is being performed. The time to design, develop, and test software is part of what drives to cost of software ever upwards. It is not at all uncommon for software costs to exceed the cost of the computer hardware.

Many home and student purchasers are shocked to find that after they have "scraped" together a few hundred dollars to purchase a computer that they still must spend \$200 or more for an office suite to do word processing, spreadsheets, and email management.

What is at the root of this dilemma? Marketing and Sales! This is the life blood of any business, so it is with software. First one must realize that software is not purchased but rather a license is obtained instead. The license is the permission to use the software. You cannot own software; you can only use it. License agreements are the legal rules governing how the software can be used. Usually the license is written such that only one computer can use the software. As a result, one must purchase the license for each computer that is to use the product. So if a business has 30 computers that need an office suite of software, 30 licenses must be purchased. Yes, one licensed CD copy could be installed on the 30 computers mentioned, but that would usually be illegal according to most license agreements. This frustrates purchasers. They have a hard time grasping that the software $\mathrm{CD}$ that they have just purchased can only be installed once.

\section{Enterprise Software}

It can get real expensive when businesses need to purchase what is referred to as enterprise software. Enterprise software is software that is used throughout a business to operate the business. This software can become pivotal to the success of a business. The enterprise software can be for Manufacturing, Sales, Accounting, or other areas of a business. Most often it is all of these areas combined into one huge package that is very expensive. An easy explanation might be a software package for a university that handles recruitment, enrollment, scholarship, registration, grades, class schedules, human resources, alumni relations, athletics, business office, accounting, grants and sponsored programs, and many other areas. These are usually very complex, integrated, software packages.

To install these huge software packages may require special hardware purchases, new employees with special skills, and lots of training for users and those that maintain the systems. The installation process may take months. In addition to the cost of installation is the very expensive software license itself. Now that the software license has been paid and the installation and training is complete, there is still one other large expense - software maintenance and upgrades. This item usually carries the title of Annual Software Support and Training in agreements with the software provider.

Most businesses are interested in repeat business; so is the software industry. The annual Software Support and Training contract is what the software vendors really want. These annual renewals are what keep a software vendor's revenue stream flowing. Vendors devise methods to "lock in" their clients to their products. That is, they want to maintain a stream of revenue generated by the Annual Software Support and Training Agreement.

\section{Shareware}

A new method for software development and distribution began in the 1980's and 1990's. This was first started by the concept of Shareware. The Shareware concept was that you can use software product for free but if you like it and plan to use it on a regular basis you should pay for the software. Therefore, Shareware was a "try it before you buy it" concept. There were several variations of this concept. One such variation was called Freeware. The idea behind this was, "I wrote, I think it's good and you can have it for free". Freeware often had a license 
agreement that would limit how it could be used. These limitations often restricted the sale of the software or may have limited it to non-commercial use.

\section{OPEN SOURCE SOFTWARE}

Software development and marketing methods that produced such products as Shareware, evolved into an important concept know as Open Source Software. But what is Open Source Software? [1] Common practice with the license purchase of marketed software is a restriction that the user will obtain an executable version of the software but not information about how the computer professionals developed it. This may be sufficient for most users. For example, "I want to use Microsoft Word to write a document. I don't care how the software works internally. I just want my document prepared using the tools supplied with the product."

It turns out that having access to the internal workings of software can be an important concept. Having access to the internal workings of software can help users break the strangle hold of vendor "lock in" mentioned earlier. This concept of Open Source means that the license agreements gives the purchaser open access to the source programming code and permission to modify it for their use. From this point there are a number of variations of what license agreement allows the user to do with modified software. The most basic of tenet of Open Source Software is that the source code is available when the software is obtained. Sometimes the software can usually be obtained for free, but always access to the internal working is always available for modification.

But do users really want to spend their time modifying the internal workings of software? Software businesses have developed around supporting Open Source Software with bug fixes and specialized versions. This concept puts the user/purchaser in more control of their software and helps eliminate many of the vendor restrictions.

\section{MISSISSIPPI AUTOMATED SYSTEMS PROJECT}

The University of Southern Mississippi (USM), in conjunction with the Open Source Software Institute (OSSI) [2], is developing a new distribution model for software [3] that is to be used by law enforcement and other justice agencies. Currently many government agencies are paying repeatedly for obtaining the same commercial application software. The premise behind this new model is to have open source application software developed using federal grants and then give the software away to government agencies. Although the software may be free of any purchase price, there may still be some substantial cost associated with installation, training, and support.

The first software component to be distributed was a Jail Management System (JMS) that is design to be used primarily by sheriffs' departments. The JMS was developed with a federal grant to the University of Southern Mississippi for use by the Mississippi Automation Systems Project (MASP). The project developed the JMS for use by 13 law enforcement agencies (city and county) on the Mississippi Gulf Coast. The JMS is currently used in several locations around the State of Mississippi and is responsible for more than 1 million inmate records.

A Department of Justice (DOJ) grant was used to develop the JMS as an Open Source software product. The JMS is designed using DOJ's Global Justice XML Data Model [4] [5]. Most jail records systems are design to be used by a single law enforcement entity. But the JMS is unique in that it is designed to allow multiple law enforcement agencies to view incarceration records of other agencies. This design will allow for agencies within metropolitan areas, states, or regions to open their inmate records to selected law enforcement agencies. It is a not an uncommon problem for an inmate to be released from a jail while the inmate is a wanted person in a nearby jurisdiction. The more widespread this data sharing becomes, the easier it will be to track wanted individuals.

\section{OPEN SOURCE SOFTWARE DISTRIBUTION MODEL}

The distribution model being developed involves several organizations working together to control new software development, support, training, installation, vendor certification, security, and distribution. The MASP/USM owns and is the controlling entity of the JMS software and will work in conjunction with the Open 
Source Software Institute (OSSI) and the Stennis Space Center in Picayune, MS for the management of the distribution process.

As an open source program, the JMS software package will be provided in 2 forms: OSS-JMS and CertJMS. The OSS-JMS will be a free package that will be available for anyone to download and use in accord with the terms of the open source license agreement. The Cert-JMS will be a certified copy of the JMS that will be available for anyone who signs an installation and support agreement with MASP/USM or one of its certified vendors. With both packages, OSS-JMS and Cert-JMS, there will be no cost for the executables and the source code will be provided. The OSS-JMS can be installed for free as a Demo version for those considering the product.

\section{OSSI}

OSSI and its National Center for Open Source Policy and Research (NCOSPR) will be responsible for preservation of and access to software components and documentation thru its software portal, GovernmentForge.org [6]. GovernmentForge.org is a firewalled repository of all software versions and system related documentation. It will serve as a communication, release, and notification center. It is the software release point for the two versions of JMS: OSS-JMS and Cert-JMS. GovernmentForge will be housed at the Stennis Space Center on secure U.S. government property. Another critical responsibility for OSSI will be version control.

\section{MASP/USM}

As the administrative entity of the project, the MASP/USM will be responsible for the software products and interactions with software clients and vendors. To become a certified vendor, a candidate must be trained, approved, and certified. Clients have the option of obtaining the OSS-JMS and installing, modifying, maintaining and operating the program under their complete control. Those clients who want support from knowledgeable vendors may obtain the Cert-JMS version and have the comfort of knowing that a knowledgeable vendor is available to assist them when questions or problems arise with the package. Responsibilities of MASP/USM will also include the training and certification of vendors, new version releases, documentation, sales and marketing, vendor and client security, software tattoos, and sales and marketing. MASP/USM will also assist law enforcement agencies in seeking grant funding to support their installation and operational costs from government agencies such as the Department of Homeland Security and the Department of Justice.

Security issues are becoming more and more demanding everyday. Issues to be addressed by MASP/USM and OSSI are:

- Who can log in (Authentication Authorization Accounting)

- Where they can log in (website/server connections)

- Where data can be sent (VPN Tunneling)

- $\quad$ Data Visibility (SSL encryption)

- $\quad$ And Entity-level Database Security more critical.

When implementing the data sharing component among agencies, the issues of security will become even

\section{PosSE}

The JMS can be a very cost effective software product for law enforcement agencies throughout the country. According to the latest U.S. Census, there are approximately 87,525 local government entities. The JMS development cost were less than $\$ 450,000$. If only $1 \%$ of the local law enforcement agencies implemented the JMS, there would be a huge payback on the government funding used for its development. It is felt that using government grant funding and the DOJ's Global Justice XML Data Model for the development of law enforcement and justice software is a cost-effective model for uniformity, standardization, security and data sharing. This same cost saving can be realized with other law enforcement software packages that will be developed. 
Plans are for the development of a suite of law enforcement software to be known as Public open source Safety Environment (PosSE). Federal funding is being sought to support this suite of software. Currently PosSE is looking to develop programs the following areas:

$\begin{array}{lll}\text { - } & \text { Police Records Management System (RMS) } \\ - & \text { Law Enforcement Automated Data System (LEADS) } \\ - & \text { UCR/NIBRS Reporting } \\ - & \text { Crime Analysis } \\ - & \text { GIS } \\ - & \text { Warrants Management System } \\ - & \text { Property, Pawn Shop, Accident, Citation, Training, Equipment, etc. } \\ & \text { Computer Aided Dispatch (CAD) } \\ & -\quad \text { Call for Service and Dispatch } \\ -\quad & \text { Mobile Data and Status system } \\ \text { - } \quad \text { Courts Records Management System } & \text { Fire Management System }\end{array}$

This list, and associated development priorities, is expected to change as this operation matures. New technologies, such as, live scan fingerprints, satellite imagery, bar coding, face recognition, infrared scan, etc., will have a major impact on software development as these technologies mature.

The JMS and future PosSE components will be Web Browser based for easier deployment and modification. The scalable nature of the PosSE suite will allow it to be used by such entities as: Police, Sheriffs, Constables, Fire Departments, Courts, and District Attorneys. These entities can be local cities, counties, metropolitan areas or regions within a state or regions that cross state boundaries. The software suite addresses the difficult problem of spending public funds for the high cost of technology by eliminating the cost of purchase. Law enforcement software seldom allows for the sharing of data among agencies. PosSE will address this problem head on. Agencies will always have the option of whether they want to share and what they want to share. Data sharing can eliminate fiefdoms, provide regional crime analysis, and allow sheriffs and police agencies to better communicate about criminal events in their responsible areas.

\section{SUMMARY}

The Jail Management System (JMS) is the first component of the PosSE Law Enforcement and Justice Suite of software. The JMS, and all of the components of the PosSE suite that are to follow, are to be released with open source licenses as no-cost products. There can be fees for installation, training, updates, and support at the option of the license subscriber. The model that has been used and will continue to be used is to seek government funding for the software development and to continue to release the software to the law enforcement communities with open source licenses as no-cost products. PosSE is to continue to be built as an integrated suite that uses DOJ standards and the Global Justice XML Data Model. Also the software repositories and accompanying version controls will be securely controlled by GovernmentForge behind the walls of the Stennis Space Center.

As a publicly funded development project, the PosSE system is designed to be freely available to any public sector criminal justice agencies to adopt and deploy without costly or prohibitive, proprietary software license restrictions.

\section{AUTHOR INFORMATION}

B. Wayne Walters holds a Masters of Science degree in Computer Science from The University of Arizona. Mr. Walters' career includes academic and professional appointments. He has experience working at the Johnson Space Center, with secure government contractors, and directing law enforcement database applications development. His interests are in open source software deployment, programming, applications design, and database systems. 


\section{REFERENCES}

1. http://www.opensource.org/docs/definition.php

2. http://www.oss-institute.org

3. Lucas, Mark Lucas and John Scott, Open Technology Roadmap, http://www.lulu.com, 2005, pg.

4. http://justicexml.gtri.gatech.edu/workshop/Day3/22_IndustryPerspective.pdf

5. http://it.ojp.gov/topic.jsp?topic_id=228

6. $\quad$ http://www.GovernmentForce.org

\section{$\underline{\text { NOTES }}$}

